\author{
ЖЕЗКАЗГАН РЕГИОНДОРУНУН ӨНӨР ЖАЙЫ ҮЧУН ДАРАК-БАДАЛ \\ ӨСУМДУКТӨРДУН ЖАНЫЛАНГАН АССОРТИМЕНТЕРИН ТУЗУУ \\ (ЖЕЗКАЗГАН ЖАНА САТПАЕВ ШААРЛАРЫНЫН МИСАЛЫНДА)
}

\author{
СОЗДАНИЕ ОБНОВЛЕННОГО АССОРТИМЕНТА ДРЕВЕСНО- \\ КУСТАРНИКОВЫХ РАСТЕНИЙ ДЛЯ ЖЕЗКАЗГАНСКОГО ПРОМЫШЛЕННОГО \\ РЕГИОНА (НА ПРИМЕРЕ ГОРОДОВ ЖЕЗКАЗГАН И САТПАЕВ)
}

\title{
UP-TO-DATE RANGE TREES AND SHRUBS FOR THE ZHEZKAZGAN INDUSTRIAL REGION (ON THE EXAMPLE OF CITIES ZHEZIKAZGAN AND SATPAYEV)
}

\begin{abstract}
Аннотация: Макалада Жезказган жана Сатпаев шаарларында жашылдандырууда колдонулган дарак-бадал өсүмдүктөрүнүн азыркы жана эски ассортиментин талдоонун жыйынтыктары берилген. Сунушталган заманбап ассортиментте 116 таксонами, анын ичинен 45 жалбырактуу, 55 бадалдуу, 5 лиана жана 11-ийне жалбырактуу өсүмдүктөру аныкталган. Жаџьы ассортиментке эскилерден болуп 45 түру кирген, ал эми анын ичинен 27 кышкы шарттарга туруксуздугунан улам, жайкы кургакчылык жана жылуулуктун туруксуздугунан жана кооздугунун төмөндүгүнөн жана жергиликтүY тургундар үчүн аллергиялык жактан жогорку даражада тургандыгынан улам альнып сальнды. Жезказган жана Сатпаев шаарларын жашылдандыруу Үчүн азыркы ассортименттеги түрлөрдүн колдонуу даражасы бааланган, ал жашыл курулушта кеңчири жана чектөөлөр боюнча аларды бөлүштүрүУ жүзөгө ашырылды.
\end{abstract}

Аннотация: В статье приводятся результаты анализа современного и старого ассортимента древесно-кустарниковых растений, используемых в озеленении городов Жезказган и Сатпаев. Определено, что современный ассортимент представлен 116 таксонами, включающими 45 лиственных деревьев, 55 кустарников, 5 лиан и 11 хвойных культур. В новый ассортимент из старого вошли 45 видов, тогда как 27 были исключеньл по причине неустойчивости к зимним условиям, летней засухе и жаре, низкой декоративности или высокой степени аллергенности для местных жителей.

Оиенена степень применения видов современного ассортимента для озеленения городов Жезказган и Сатпаев, осуществлено их ранжирование по широко $u$ ограниченности используемые в зеленом строительстве.

Annotation: The article presents the results of the analysis of the modern and old range of trees and shrubs used in landscaping cities Zhezkazgan and Satpayev. It is determined that the modern range is represented by 116 taxa, including 45 deciduous trees, 55 shrubs, 5 vines and 11 conifers. The new assortment of the old included 45 species, while 27 were excluded due to instability to winter conditions, summer drought and heat, low decorative or high degree of allergenicity for local residents.

Evaluated the extent to which the modern range for gardening of the cities of Zhezkazgan and Satpaev implemented their ranking on widely used and limitations in green building.

Негизги сөздөр: Жезказган өнөр жай аймагы, Жезказган, Сатпаев, дарактуу флора, өсүмдүктөр, жашыл куруу.

Ключевые слова: Жезказганский промышленный регион, Жезказган, Сатпаев, древесная флора, растения, зеленое строительство. 
Key words: Zhezkazgan industrial region, Zhezkazgan, Satpayev, wood flora, plants, green building

Современные городские условия характеризуются высоким уровнем загрязненности, что особенно заметно на примере промышленных регионов [1].

Карагандинская область (Республика Казахстан) является одним из промышленныхцентров, на территории которой размещены такие промышленные города, как Караганда, Балхаш, Темиртау, Жезказган и Сатпаев [2, 3]. Последние два населенных пункта образуют Жезкзаганский промышленный регион. Данный регион ориентирован на добычу и переработку медной и марганцевой руды.

Особенность данного региона связана также с тем, что, помимо промышленной нагрузки на окружающую среду, отмечены сложные климатические условия. Климат резко-континентальный и аридный, характеризующийся высокими летними температурами и острым дефицитом осадков, а также холодными и малоснежными зимами $[4,5]$.

Одним из способов улучшения состояния городской среды является развитие зеленого строительства. Древесная культурная флора позволяет снижать уровень загрязненности, увеличивать влажность воздуха, поглощать загрязняющие вещества из атмосферы и почвы, имеет важный эстетический эффект.

Поэтому создание современного адаптивного ассортимента древеснокустарниковых насаждений [6, 7] является важной задачей интродукции растений и организации зеленого строительства.

Цель настоящего исследования - провести сравнение современного озеленительного ассортимента растений для городов Сатпаева и Жезказгана с ранее используемым в данном регионе.

В рамках исследований осуществляли сравнение современного видового состава древесно-кустарниковых растений $(2017$ г.) с ранее разработанным (1979 г.) для Жезказганского промышленного региона [8].

Начало озеленения для городов Жезказган и Сатпаев относится к 30-40 гг. прошлого столетия, что было связано с освоением медных месторождений и строительством обогатительных фабрик и медного завода [9]. Ранее планомерные интродукционные исследования не проводились, поэтому зеленое строительство велось на основе результатов интродукции по г. Караганде [10].

Ранее выпущенный рекомендательный ассортимент древесно-кустарниковых растений включал 224 таксонов, в том числе 5 хвойных, 29 лиственных и 38 кустарников. То есть общее число рекомендованных видов древесно-кустарниковых растений составил 72 наименования.

Для древесных растений указаны типы посадок, зимостойкость, отношение к освещению, засухоустойчивость, требовательность к плодоношению, форма кроны, дымо, пыле-, газоустойчивость, а также приведены рекомендации по способам выращивания изученных растений в питомнике и городских насаждениях.

Был накоплен определенный ассортимент декоративных растений для озеленения и практического садоводства в регионе. Однако вместе с современными методами садового дизайна, с использованием инертных материалов и малых архитектурных форм в озеленении на смену устаревшему ассортименту приходят качественно новые сорта и виды древесных культур.

Современный сформированный ассортимент включает 116 видов древесных растений (таблица 1), который включает 45 лиственных деревьев, 55 кустарников, 5 лиан и 11 хвойных культур. 
Таблица 1 - Древесно-кустарниковые растения, рекомендованные в озеленениеЖезказганского промышленного региона (современный ассортимент)

\begin{tabular}{|c|l|l|}
\hline \multicolumn{1}{|c|}{ Ho } & \multicolumn{1}{|c|}{ Лазвание вида, сорта, формы, гибрида } & Рекомендованный город \\
\multicolumn{1}{|c|}{ для озеленения }
\end{tabular}




\begin{tabular}{|c|c|c|}
\hline 45 & Amelanchier spicata (Lam.) K.Koch. & Ж \\
\hline 46 & Amelanchier oligocarpaRoem. & Ж \\
\hline 47 & ViburnumopulusL.* & ЖС \\
\hline 48 & Caragana arborescens Lam.* & ЖС \\
\hline 49 & Caragana microphylla Lam. & ЖС \\
\hline 50 & Catalpa speciosa (Warder ex Barney) Engelm. & ЖС \\
\hline 51 & Cotoneaster lucidus Schltr. & Ж \\
\hline 52 & Cotoneaster melanocarpus Lodd. & ЖС \\
\hline 53 & Clematis viticella $\mathrm{L}$. & Ж \\
\hline 54 & Clematis virginiana $\mathrm{L}$. & Ж \\
\hline 55 & Acer ginnala Maxim. & ЖС \\
\hline 56 & Acer semenovii Regel et Herd. & ЖС \\
\hline 57 & Acer tataricum L.* & ЖС \\
\hline 58 & Acer negundo L.* & ЖС \\
\hline 59 & LarixsibiricaLedeb. & ЖС \\
\hline 60 & Tilia platyphyllos Scop. & ЖС \\
\hline 61 & Elaeagnus oxycarpa L.* & ЖС \\
\hline 62 & AmygdalusnanaL. & ЖС \\
\hline 63 & Juniperus horizontalis Moench & ЖС \\
\hline 64 & Juniperus virginiana L.* & ЖС \\
\hline 65 & Juniperus sabina L. & ЖС \\
\hline 66 & Juniperus pseudosabina Fisch.et C.A.Mey. & ЖС \\
\hline 67 & Juniperus communis $\mathrm{L} . *$ & ЖС \\
\hline 68 & Juniperus sargentii (Henry) Takeda & Ж \\
\hline 69 & Menispermum dauricum DC. & Ж \\
\hline 70 & Ptelea trifoliata $\mathrm{L}$. & Ж \\
\hline 71 & Robinia pseudoacacia $\mathrm{L}$. & Ж \\
\hline 72 & Rosa beggeriana Schrenk ex Fisch.et Mey.* & ЖС \\
\hline 73 & Rosa canina $\mathrm{L}$. & ЖС \\
\hline 74 & Rosa cinnamomea $\mathrm{L}$. & ЖС \\
\hline 75 & Rosa rugosa Thunb. & ЖС \\
\hline 76 & RosalaxaRetz. & ЖС \\
\hline 77 & Sorbaria sorbifolia (L.) A.Braun & Ж \\
\hline 78 & Securinega suffruticosa (Pall.) Rehder & Ж \\
\hline 79 & Syringa amurensis Rupr. & ЖС \\
\hline 80 & Syringa josikaea Jasq. f. ex Rchb.* & ЖС \\
\hline 81 & Syringa wolfii C.K.Schneid. & Ж \\
\hline 82 & Syringa komarowii C.K.Schneid. & Ж \\
\hline 83 & Syringa vulgaris L. * & ЖС \\
\hline 84 & CotinuscoggygriaScop. & ЖС \\
\hline 85 & PrunusspinosaL. & ЖС \\
\hline 86 & Prunus stepposa Kotov. & ЖС \\
\hline 87 & Ribes aureum Pursh* & ЖС \\
\hline 88 & Symphoricarpos albus $\mathrm{L}$. & ЖС \\
\hline 89 & Pinus sylvestris L.* & ЖС \\
\hline 90 & Spiraea salicifolia $\mathrm{L}$. & ЖС \\
\hline 91 & Spiraea trilobata $\mathrm{L}$. & ЖС \\
\hline 92 & Populus balsamifera L.* & ЖС \\
\hline 93 & Populusalba L. & ЖС \\
\hline 94 & Populus laurifolia Ledeb. & ЖС \\
\hline
\end{tabular}




\begin{tabular}{|c|c|c|}
\hline 95 & Populus canadensis Moench & ЖС \\
\hline 96 & Thuja occidentalis L. & $\mathrm{C}$ \\
\hline 97 & Padus virginiana (L.) Mill.* & ЖС \\
\hline 98 & PadusaviumMill.* & ЖC \\
\hline 99 & FraxinusamericanaL.* & ЖC \\
\hline 100 & Fraxinus excelsior L.* & ЖC \\
\hline 101 & Fraxinus pennsylvanica Marsh. & ЖC \\
\hline 102 & TamarixramosissimaLedeb. & ЖС \\
\hline 103 & TamarixelongataLedeb. & ЖC \\
\hline 104 & TamarixlaxaWilld. & ЖС \\
\hline \multicolumn{3}{|c|}{ Цветущие древесно-кустарниковые растения } \\
\hline 105 & RosapolyanthaHort. 'АвеМария' & ЖC \\
\hline 106 & Rosapolyantha'Вечерний Мотив' & ЖС \\
\hline 107 & RosaL. hybridtea'GloriaDei' & ЖС \\
\hline 108 & Rosa hybridtea'Opera' & Ж \\
\hline 109 & Rosa hybridtea'Pascali' & Ж \\
\hline 110 & Rosahybridtea'SophiaLoren' & Ж \\
\hline 111 & Rosa hybrid tea 'Super Star' & Ж \\
\hline 112 & Rosa hybridtea'Tineke' & Ж \\
\hline 113 & Rosa hybridtea'Былина' & Ж \\
\hline 114 & Syringa $\mathrm{x}$ chinensis Willd. & Ж \\
\hline 115 & Syringa komarowii Schneid. & Ж \\
\hline 116 & Syringa vulgaris L. 'Belle de Nancy' & Ж \\
\hline
\end{tabular}

В ассортименте приводятся название видов, форм и сортов, краткая экологофизиологическая характеристика (отношение к почве, засухоустойчивость, устойчивость к засолению, затенению, отношение к условиям увлажнения, необходимость укрытия на зимний период). Для каждой культуры описано возможности использования в озеленении, как применение в одиночных и групповых посадках, для создания парков, сквером, для формирования живой изгороди, для покрытия невысоких стен, озеленения беседок, балконов, для декорирования склонов и беседок и другое.

Нами проведено сравнение предыдущего ассортимента с вновь разработанным списком. В новый ассортимент из старого списка вошли 45 вида, 27 таксонов были исключены (таблица 2).

\section{Таблица 2 - Исключенные виды древесно-кустарниковых растений из современного ассортимента для Жезказганского промышленного региона}

\begin{tabular}{|c|l|l|}
\hline № & \multicolumn{1}{|c|}{ Вид } & \multicolumn{1}{|c|}{ Причины исключения } \\
\hline 1 & Аморфа голая & $\begin{array}{l}\text { Вымерзание в зимний период, особенно в } \\
\text { малоснежные зимы }\end{array}$ \\
\hline 2 & Аморфа калифорнийская & Невозможность семенного размножения \\
\hline 3 & Береза киргизская & $\begin{array}{l}\text { Плохо переносит сухость атмосферного } \\
\text { воздуха, наблюдается полный опад листьев в } \\
\text { середине лета }\end{array}$ \\
\hline 5 & Боярышник вееровидный & $\begin{array}{l}\text { Плохо переносит сухость атмосферного } \\
\text { воздуха, наблюдается полный опад листьев в } \\
\text { середине лета }\end{array}$ \\
\hline 6 & $\begin{array}{l}\text { Виноградовник } \\
\text { короткоцветоножковый }\end{array}$ & \\
\hline 7 & Виноградовник разнолистный & \\
\hline
\end{tabular}




\begin{tabular}{|c|c|c|}
\hline 8 & Жимолость Королькова & \\
\hline 9 & Жимолость смешанная & \\
\hline 10 & Ирга обильноцветущая & Быстро выпадает из культуры - на 3-4 год \\
\hline 11 & Карагана колючая & \multirow{2}{*}{$\begin{array}{l}\text { Очень колючие формы растений, трудны в } \\
\text { посадке и уходе за посадками }\end{array}$} \\
\hline 12 & Карагана короткоиглая & \\
\hline 13 & Карагана туркестанская & \multirow{3}{*}{$\begin{array}{l}\text { Вымерзает в зимний период на высоту } \\
\text { снежного покрова }\end{array}$} \\
\hline 14 & Клен туркестанский & \\
\hline 15 & Курильский чай даурский & \\
\hline 16 & Ломонос лигустиковый & $\begin{array}{l}\text { Очень медленно растет, плохо переносит } \\
\text { пересадку }\end{array}$ \\
\hline 17 & Роза илийская & \multirow{5}{*}{$\begin{array}{l}\text { Вымерзает в зимний период на высоту } \\
\text { снежного покрова }\end{array}$} \\
\hline 18 & Сирень бархатная & \\
\hline 19 & Сирень Генри & \\
\hline 20 & Сирень гималайская & \\
\hline 21 & Сирень мохнатая & \\
\hline 22 & Смородина альпийская & \multirow{4}{*}{$\begin{array}{l}\text { Крайне чувствительный вид к атмосферной } \\
\text { сухости воздуха }\end{array}$} \\
\hline 23 & Таволга ильмолистная & \\
\hline 24 & Сумах ароматный & \\
\hline 25 & Тополь дельтовидный & \\
\hline 26 & Тополь черный & Дает обильный пух, аллергенный вид \\
\hline 27 & Трескун амурский & $\begin{array}{l}\text { Крайне чувствительный вид к атмосферной } \\
\text { сухости воздуха }\end{array}$ \\
\hline
\end{tabular}

Причинами исключения видов, приведенных в таблице 2, являются непригодность для озеленения, вымерзание в зимний период или крайняя чувствительность к летней засухе, медленный рост.

Стоит отметить, что ряд культур нашли широкое применение в озеленении городов Сатпаев и Жезказган, тогда как другие таксоны - используются редко, либо совершенно не используются, несмотря на свой потенциал.

Широкое применение в озеленении находят следующие виды: береза пушистая, боярышник кровава-красный, виноград девичий пятилисточковый, вяз гладкий, вяз перисто-ветвистый, ель колючая, сосна обыкновенная, жимолость татарская, ива вавилонская, ива козья, калина обыкновенная, карагана древовидная, клен ясенелистный, клен татарский, смородина золотистая, тополь бальзамический, тополь черный, тополь серебристый, сирень венгерская и другие.

Более редко в озеленении применяются абрикос обыкновенный, барбарис обыкновенный, барбарис разноножковый, береза бородавчатая, боярышник алтайский, бирючины обыкновенная, бузина кистистая, вишня войлочная, вишня кустарниковая, груша Регеля, дуб черешчатый, ель обыкновенная, жостер слабительный, ирга колосистая, катальпа прекрасная, лиственница сибирская, можжевельник виргинский, робиния псевдоакация, роза Беггера, терн, туя западная и другие.

Очень редко встречаются в озеленительной практике (отмечены только для частных приусадебных участков) такие виды, как аморфа кустарниковая, барбарис амурский, барбарис монетовидный, кизильник черноплодный, клематис фиолетовый, клен Гиннала, клен Семенова, липа сердцевидная, миндаль степной, можжевельник горизонтальный, скумпия кожевенная,

Не находят свое место в озеленении такие виды, как барбарис весенний, барбарис корейский, боярышник шарлаховый, дерен Бейля, дерен белый, жимолость Мака, кизильник блестящий, луносемянник даурский, птелея трехлистная, сикуринега полукустарниковая, 
Хотя интродукционные исследования на территории Жезказганского ботанического сада показали устойчивость данных культур и возможность их внедрения в зеленое строительство региона.

Таким образом, только 15 видов древесно-кустарниковых растений из 34 нашли применение в озеленении городов Жезказган и Сатпаев; 15 видов - применяются для частного сектора, 4 вида - не используются в озеленении.

\section{Список использованной литературы:}

1 Фрей Т.Э. Влияние промышленных предприятий на окружающую среду. - М.: Издво АН СССР, 1987. - 212 с.

2 Информационный бюллетень о состоянии окружающей среды Республики Казахстан. - Астана: РГП Казгидромет, 2016. - Вып. 09 (203). - С. 116-118.

3 Жакатаева Б.Т. Антропогенные составляющие атмосферного загрязнения в Центральном Казахстане // Материалы межд.науч.-практ.конф., посвященные 80-летию академика Е.А. Букетова. - Караганда, 2015. - С. 120-127.

4 Урумов Т.М. Краткая географическая и климатологическая характеристика Жезказганского промышленного района // В кн. Большой Жезказган. - Алматы: Полиграфкомбинат, 1994. - С. 14-16.

5 Максутова П.А., Дюсекеева Ш.Е., Кулмаганбетова А.О. Физическая география Карагандинской области. - Караганда, 2005. - 59 с.

6 Байтулин И.О., Проскуряков М.А., Чекалин С.В. Системно-экологический подход к интродукции растений в Казахстане. Ч.1. - Алма-Ата, 1992. - 198 с.

7 Горохов А.В. Городское зеленое строительство. - М.: Стройиздат, 1991. - 416 с.

8 Ассортимент декоративных растений для озеленения Джезказганского промышленного района. - Алма-Ата, 1979. - 40 с

9 Статистический бюллетень. Основные показатели работы промышленности, 2010 $\Gamma$.

10 Ассортимент декоративных растений для озеленения промышленных центров Карагандинской области. - Алма-Ата, 1978. - 46 с.

Рецензент: к.б.н., доцент Жезканского университета им. О.А. Байконурова Г.Ж. Мырзалы 